
- The pressures of economic development and the resulting conversion of land uses has changed both the appearance and biology of much of the California landscape.

The population and economic growth of the 20th century altered the landscape and the state's natural resources in fundamental ways. Unlike the two preceding centuries, 21st-century California will not rely on the extraction of natural resources for economic well-being to any significant extent. Yet, there are reasons to believe that the pressures will grow and intensify. Indeed, the significant changes that occurred in the 20th century may pale beside those that could be in store for the next.

By 2025, California's population is expected to grow by nearly $50 \%$; new technology with unknown side effects will develop at a quickening pace; and the state's economy will be buffeted by unpredictable pressures from the global economy in which it is likely to be firmly embedded. The challenge of managing California's natural resources in the face of such change is daunting, but it is imperative that we meet the challenge since natural resources will be more critical than ever in determining our economic welfare and whether California remains a pleasant and hospitable place to live.

In this second issue of the special California Agriculture series, "Future in Focus: 2000-2025," UC faculty from the Division of Agriculture and Natural Resources (ANR) examine the state of our resources as we enter the 21st century and the adequacy of existing arrangements for managing them. Several themes emerge. First, California's resource base will continue to undergo intensifying pressures as our population and economy grow. Unless effectively managed, population and economic growth will lead to significant declines in the quality of our air and water resources and will threaten the productivity of California's lands.

Second, the centuries-long trend of environmental deterioration must be reversed if serious and costly consequences are to be averted. Continued extinction of species and consequent loss of biological diversity; the degradation and loss of services provided by the environment; and

The pressures on California's natural resources will grow and intensify in the 21st century. Our scenic wonders range from the Pacific Ocean at Big Sur, above, to the Sierra Nevada to Death Valley. Facing page, The stunning beauty of the Yosemite Valley inspired early conservationists; although a secure resource, the national park is threatened by pollution and overuse.

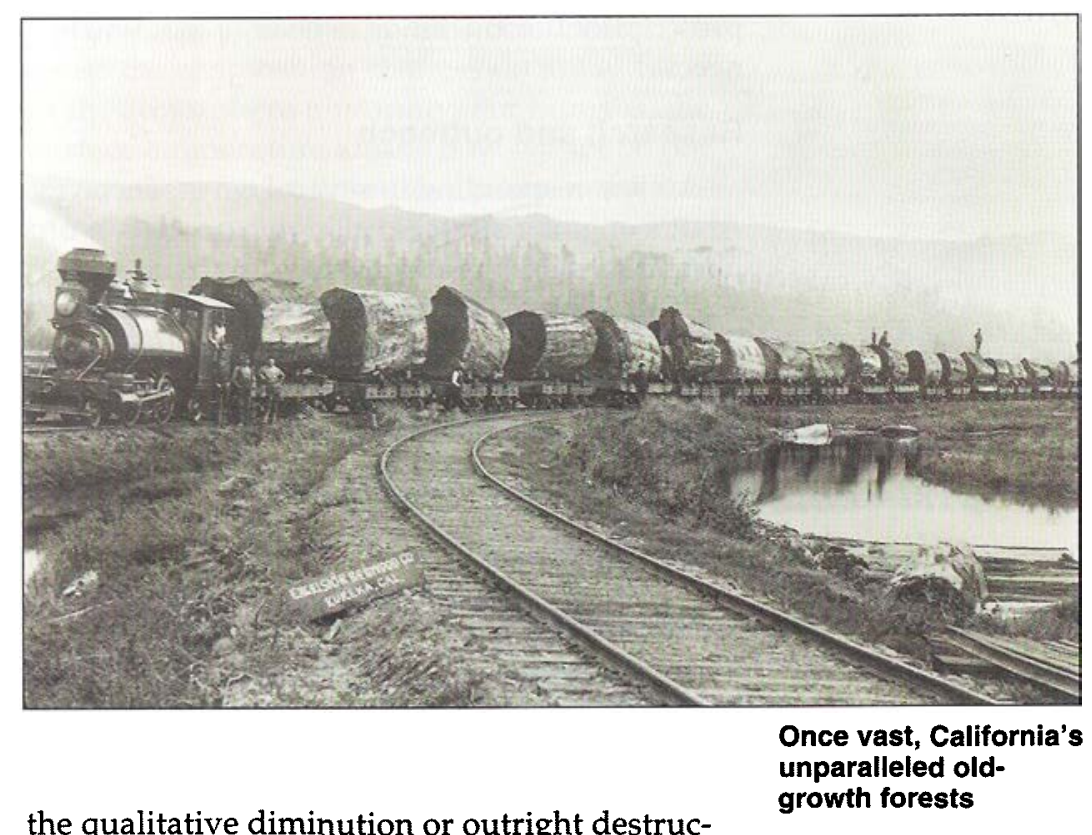

the qualitative diminution or outright destruction of significant aesthetic resources will be costly to mitigate should they be permitted to occur.

have been whittled down to several hun-

Finally, the institutions which Californians have relied upon to manage their natural resources are not well or appropriately constituted to address many of the challenges. Funda- 


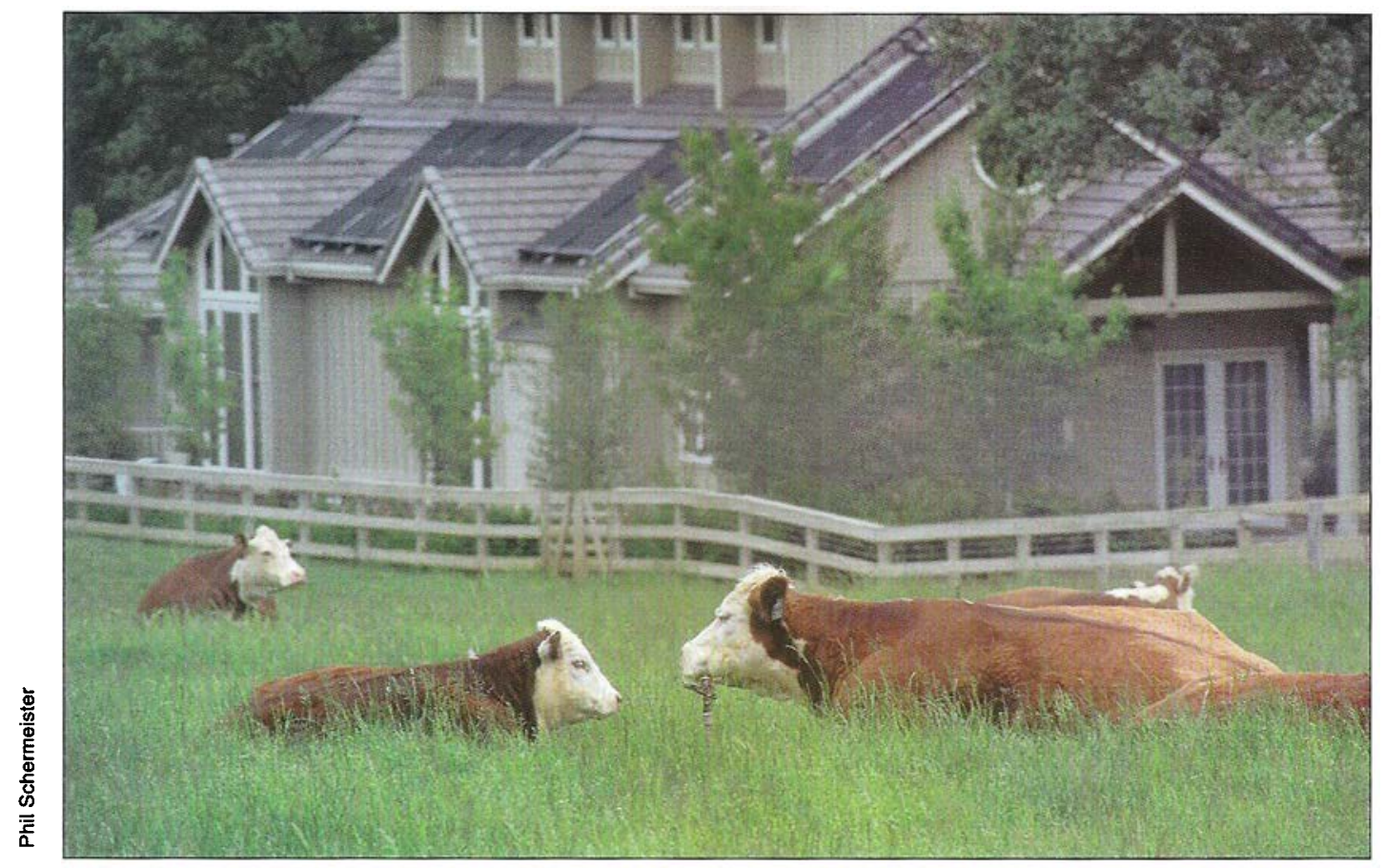

Population and economic growth have altered the landscape in fundamental ways. In Placerville, cattle graze near a residential development, demonstrating the narrowing urbanagricultural interface statewide.

mental changes will be needed in our land- and water-management institutions, some of which were created in response to circumstances of the 19 th century. Taken collectively, the papers constitute a call for action as well as an illustrative prescription for the kinds of change that will be needed.

\section{Research and outreach}

ANR is responding in several ways. Through ANR's ongoing strategic planning process, we have identified high-priority research programs, which should lead

Unlike the two preceding centuries, 21st-century California will not rely on the extraction of natural resources for economic well-being to any significant extent. to the development of new and innovative methods for managing the state's land, air and water. Examples include programs to restore watersheds and improve management of waste streams. New funding and reallocations from lowpriority activities will pay for these programs. Among the Division's top priorities are the development of new farm production techniques and technologies that conserve natural resources and help agriculture complement the environment.

In addition, ANR faculty are prepared to work directly with legislators, state and local government officials, and interested members of the public to help ensure that the best possible policies and practices are employed to meet new challenges of natural-resource management. A recent example is an informal symposium convened last November that involved face-to-face discussions between key legislators and UC experts on several critical waterpolicy issues. These discussions were intended to be a precursor to the introduction of important new water legislation later this year. The premise of the symposium was that policy-making ought to begin with and be based upon the best science available. It is the responsibility of ANR (as well as the larger University) to ensure that up-to-date scientific information is available to legislators. The leadership of both the state legislature and ANR intend to build on the success of the water meeting and develop others on a wide variety of topics. These meetings have the potential to facilitate the development of innovative and effective policies for resources in the future.

All Californians have a stake in the maintenance and enhancement of the state's natural resources. If our resources are to remain healthy, productive and attractive, new and innovative policies, technologies and techniques will be required. ANR is prepared to do its share by according high priority to programs of research and outreach that will respond effectively to the new challenges of resource management. 